\title{
O SAMU, a regulação no Estado do Rio de Janeiro e a integralidade segundo gestores dos três níveis de governo
}

\section{| ${ }^{1}$ Gisele O’Dwyer, ${ }^{2}$ Ruben Araujo de Mattos |}

Resumo: O SAMU é uma política prioritária para o atual governo. $\mathrm{O}$ objetivo do estudo foi discutir o potencial de sua prática de integralidade, analisando a assistência às urgências por meio de atores importantes da gestão. A metodologia baseou-se na Teoria da Estruturação de Giddens, relacionando estrutura e ação, que foi investigada na consciência discursiva. Foram entrevistados gestores dos três entes federativos que versaram sobre a regulação nos SAMU do estado do Rio de Janeiro. Os eixos de análise foram: o SAMU, suas características, atribuições e a questão social; o médico, seu perfil, atitudes e a decisão clínica; e a assistência em rede, a gestão e a regulação. Foi indicado que não havia assistência integrada por conta da insuficiência estrutural da atenção básica e da precariedade nos hospitais de referência. A capacitação profissional e os vínculos empregatícios precários obstaculizavam a gestão nos SAMU. Havia inoperância dos comitês gestores dos diversos níveis de atuação, e não havia produção de informação. Foi destacado o privilégio da regulação como observatório do sistema e da atenção às urgências para avaliar o desempenho da rede e para a regionalização da assistência.

> Palavras-chave: SAMU; integralidade; atendimento às urgências; políticas de urgência.

\footnotetext{
${ }^{1}$ Doutora em Saúde Pública pelo IMS/UERJ. Pesquisadora do DAPS/ENSP/FIOCRUZ Endereço eletrônico: odwyer@ensp.fiocruz.br

${ }^{2}$ Doutor em Saúde Pública pelo IMS/UERJ. Pesquisador do IMS/ UERJ. Endereço eletrônico: ruben@ims.uerj.br .
}

Recebido em: 25/10/2010. Aprovado em: 17/06/2011. 
A Política Nacional de Atenção às Urgências - PNAU (BRASIL, 2003a) regulamentou a área de urgência no Brasil por meio de um conjunto de portarias e documentos. Destacamos como determinações da PNAU: integração dos níveis assistenciais na atenção às urgências; a regulação médica; a capacitação pelos Núcleos de Ensino em Urgência (NEU); a regionalização; a gestão por comitês de urgência nos níveis municipal, regional, estadual e nacional; e a humanização e assistência centrada no usuário.

A formulação da política de urgência aconteceu em um cenário de muita insatisfação com o atendimento nas emergências hospitalares, suas filas e superlotação. $\mathrm{O}$ grande acúmulo de doentes nos serviços de emergência ocorria tanto no setor público como no privado, tanto no Brasil como no exterior (O'DWYER et al., 2008; HOLLANDER; PINES, 2007; KALEMOGLU et al., 2004; e TANNEBAUM; ARNAOLD, 2001).

Um estudo sobre utilização inadequada de serviços de emergência reforça que eles devem ser utilizados em circunstâncias específicas, e que a utilização inadequada é prejudicial para os pacientes graves e para os não graves, porque esses últimos, ao elegerem o hospital para seu atendimento, não têm garantido o atendimento de seguimento (CARRET et al., 2009). Uma revisão sistemática sobre intervenções propostas para solucionar a superlotação dos serviços de emergência desmistificou as barreiras de acesso como efetivas para conter a superlotação (BITTENCOURT; HORTALE, 2009). Segundo os autores, a superlotação revela o baixo desempenho do hospital e da rede. Eles estacam, ainda, os serviços de urgência como representantes do desempenho dos serviços de saúde (BITTENCOURT; HORTALE, 2009).

O Serviço de Atendimento Móvel de Urgência - SAMU (BRASIL, 2003b) foi o primeiro componente da PNAU a ser implantado. É um serviço de socorro pré-hospitalar móvel, no qual o usuário, por meio do acesso telefônico gratuito pelo número 192, solicita atendimento. Apresenta um componente regulador (a Central de Regulação) e um componente assistencial (a equipe das ambulâncias). Na regulação, todas as etapas do atendimento são registradas no computador e gravadas. A TARM (Telefonista Auxiliar de Regulação Médica) atende ao telefone e faz a identificação e localização do paciente. Os reguladores registram diagnóstico, conduta e destino do paciente. Orientam 
e decidem qual o tipo de ambulância que prestará o atendimento. A USB

(Unidade de Suporte Básica) opera com um técnico de enfermagem, e recursos tecnológicos mais simples. A USA (Unidade de Suporte Avançada) tem como profissionais um médico, um enfermeiro, além de mais recursos tecnológicos. Os RO (Radio-operadores) são responsáveis pelo contato com as ambulâncias e pelo acompanhamento do atendimento.

Esse novo serviço pretende organizar o acesso aos serviços de emergência hospitalar, ao leito hospitalar e à rede de forma mais ampla, propiciando o atendimento integral às urgências em todos os níveis de atenção do sistema.

Portanto, o SAMU consiste numa nova porta de entrada no sistema, acontecendo a partir das chamadas telefônicas e atendimento por ambulância, conforme critérios de gravidade.

Desde 2003, houve uma expansão contínua de SAMU e, em julho de 2010, existiam 151 SAMU em 1286 municípios, com previsão de atingir aproximadamente 162 milhões de habitantes ao final de 2010 (dados do site do Ministério da Saúde). O serviço exige grande investimento em financiamento, em organização do trabalho e em qualificação de recursos humanos. O conhecimento exigido para essa atividade é regulado pela PNAU, e os novos profissionais contratados devem ser treinados segundo critérios estabelecidos para cada tipo de atividade.

O SAMU pode ser uma nova oportunidade de expressão do descompasso entre as necessidades de saúde e a disponibilidade de ações de saúde. Por isso, pretende ser observatório do sistema de saúde.

Analisamos uma prática advinda de uma nova política, que trata de um problema complexo (a atenção às urgências), com grande impacto nos indicadores de morbimortalidade, mas que, ao mesmo tempo, é vista como uma oportunidade de diagnóstico da insuficiência da atenção. Por isso, interessava-nos a integralidade praticada no SAMU, enquanto valor e como forma de organizar os serviços, mas pronta a assimilar necessidades não previstas, aproveitando ao máximo essa nova forma de encontro profissionalusuário para a legitimação do SUS (MATTOS, 2001).

Entendemos que a integralidade é um princípio do SUS que qualifica suas práticas e o legitima perante a população. Um primeiro marco da integralidade proposta para a atenção às urgências foi a definição das responsabilidades dos 
diferentes níveis de assistência, integrando os serviços para atender a esse nível de atenção, além de se apoiar na regionalização.

A maior expectativa de cumprimento da integralidade no SAMU estaria na integração entre serviços, um dos seus sentidos mais tradicionais. O sentido mais sistêmico, de resposta governamental a uma necessidade, foi cumprido a partir da implantação do componente pré-hospitalar. E o potente sentido da integralidade, de encontro bem-sucedido entre paciente e profissional, foi sugerido pelos documentos norteadores que propuseram conceitos ampliados de urgência e atendimento centrado no usuário (MATTOS, 2001).

Reiteramos que, apesar de a distinção dos "sentidos" da integralidade ser útil para análise, consideramos que a integralidade não pode ser cumprida apenas em um sentido, já que ela indica uma opção técnica e política.

Utilizamos a Teoria da Estruturação (GIDDENS, 1984), identificada como uma estratégia metodológica que permite uma reflexão a partir do conhecimento de uma dada estrutura e de uma interpretação das consequências da ação a partir do acesso ao agente. Esse acesso pode dar-se por meio da consciência discursiva e da consciência prática (GIDDENS, 1984).

Uma das formas de interpretar a ação seria acessar o agente por intermédio do seu discurso, como forma de "elucidar os processos concretos da vida social" e permitir uma maior reflexividade dos atores sobre sua prática. Para Giddens, as práticas sociais podem ser entendidas como procedimentos, métodos ou técnicas hábeis executadas apropriadamente pelos agentes sociais, utilizando-se regras e recursos, que compóem a estrutura. $\mathrm{O}$ aspecto normativo das regras refere-se às práticas, do ponto de vista dos direitos e obrigações e dos modos pelos quais essas práticas podem ser executadas. $\mathrm{O}$ aspecto semântico das regras refere-se ao significado qualitativo e processual das práticas, associadas ao seu desempenho. Os recursos são as facilidades ou base de poder a que o agente tem acesso e que ele manipula para influenciar a interação com o outro. Os recursos podem ser autoritativos (cargo que ocupa, por exemplo) ou alocativos (materiais) (O'DWYER; MATTOS, 2010). No SAMU, a estrutura estaria representada pelos recursos indicados por portarias, como a composição da equipe e quantitativo de ambulâncias, sugeridos em função do número de habitantes.

A fim de dar expressão à consciência discursiva dos atores, optamos por entrevistar gestores sobre o atendimento integral às urgências a partir do componente 
regulador do SAMU, já que é na regulação que são definidas ações a partir de uma estrutura interna (as ambulâncias e profissionais) e externa (os recursos da rede).

Para o campo, elegemos o estado do Rio de Janeiro, por sua especificidade. $\mathrm{O}$ estado implantou seus dois primeiros SAMU, ambos regionais, bem precocemente em relação ao restante do país, e em um momento em que os SAMU implantados eram predominantemente municipais (MACHADO et al., 2011). O terceiro SAMU implantado no estado foi municipal, o segundo maior do Brasil. Portanto, o Rio de Janeiro se destaca na implantação do serviço em alguns aspectos: por ter tido uma implantação exclusivamente metropolitana até meados de 2010; por ter abrigado o primeiro SAMU regional do Brasil e dois dos três maiores SAMU do país; e por ter uma coordenação estadual de urgência sob a gestão da Corporação dos Bombeiros. O estado do Rio de Janeiro já tinha uma tradição no atendimento pré-hospitalar móvel de emergências ocorridas em vias públicas desde 1986, por meio da atuação do Grupamento de Socorro de Emergência (GSE) do Corpo de Bombeiros Militar do Estado do Rio de Janeiro (CBMERJ), pioneiro no Brasil nesse tipo de atividade.

Outra característica que tem impactado a assistência às urgências no estado e, em especial, no município do Rio de Janeiro, é a desproporção de unidades hospitalares em relação à atenção básica. Essa complexa rede hospitalar pública divide sua gestão entre o município, estado, união, além de entidades filantrópicas e universidades, o que vem dificultando a integração da rede, assim como a com o SAMU.

Foram entrevistados o Coordenador Geral de Urgência/Emergência (CGUE) do Ministério da Saúde, os coordenadores dos três SAMU do estado, o coordenador estadual de U/E da Secretaria de Saúde e de Defesa Civil do estado (SESDEC) e um membro do Comitê Gestor Nacional, o representante da Rede Brasileira de Cooperação em Urgências (RBCE). Escolhemos esse último porque essa rede, além de representar os profissionais da emergência, tem tido participação decisiva junto ao nível central, inclusive na formulação das políticas de urgência. Com a seleção desses atores pudemos entrevistar gestores do nível central, estadual e local.

Compôs o roteiro de entrevista a compreensão da integralidade nos seus três sentidos abordados. A expectativa de atuação do SAMU traduziu o sentido de integralidade que representa a capacidade do governo em dar resposta a uma 
necessidade; a relação com a rede traduziu o sentido de integração entre serviços; e a atividade de regulação traduziu a postura profissional. A análise das falas evidenciou, por meio da consciência discursiva, como os atores atribuem valor e mobilizam as regras e recursos disponíveis no SAMU, produzindo uma regulação que pode ou não contribuir com a integralidade.

As categorias centrais analisadas foram: o SAMU, suas características, atribuições e a questão social; o médico, seu perfil, atitudes e a decisão clínica; e a assistência em rede, a gestão e a regulação.

Este trabalho foi submetido ao Comitê de Ética em Pesquisa do Instituto de Medicina Social / Universidade do Estado do Rio de Janeiro, e aprovado sob o $\mathrm{n}^{\circ}$. CAAE 0006.0.259.000-08.

\section{O SAMU, suas características, atribuições e a questão social}

O SAMU foi proposto para responder a um vazio assistencial, a urgência préhospitalar, contribuindo para o atendimento integral às urgências. Para os entrevistados, a proposta documental sobre o SAMU compunha um recurso estrutural facilitador para a rede. De forma unânime, foi ressaltado o potencial do atendimento às urgências para a consolidação do SUS ("Não tem SUS que preste se não acolher a urgência"). Portanto, houve acordo entre os gestores de que o SAMU cumpria a integralidade por responder a uma necessidade em saúde. A integralidade a partir da articulação entre os serviços também foi apontada ("Facilita o acesso ao sistema").

Outro aspecto importante sobre esse nível de atenção é sua representatividade do desempenho do sistema ("Urgência como espelho do desempenho do SUS"; e "O SAMU faz observação do estado de saúde da população e da resolutividade da rede de serviços"). Foi indicada a prioridade desse nível de atenção, assim como o aspecto de que ele recebe demandas geradas pelos vazios assistenciais da rede, expondo sua fragilidade ("Tudo que não deu certo vai pro SAMU”). Portanto, tanto os aspectos normativos quanto os semânticos das regras estruturais que o SAMU representa foram considerados pelos gestores como recursos facilitadores para o SUS.

O SAMU é um recurso que compensa ausências estruturais do Sistema Único de Saúde ("É porta de entrada do sistema”). Essa é uma atribuição da urgência 
induzida pela deficiência de portas de entrada mais qualificadas. A atenção básica é a porta de entrada presumida do sistema, mas, como a média complexidade e a referência hospitalar também estavam estruturalmente deficientes para a rede local, a demanda por porta de entrada impacta o SAMU. A falta do espaço assistencial na atenção básica propiciou situações não esperadas, como a relatada por um dos entrevistados: "Ligam chamando 'meu médico'."

Essa situação é satisfatória, pelo potencial que a regulação tem de prestar um bom atendimento, compatível com a integralidade no seu sentido mais relacional e enquanto valor, refletindo a capacidade do agente de fazer bom uso dos recursos disponíveis (“SAMU transmite segurança social”). Entretanto, há um lado perverso nessa identificação pessoal com o médico regulador, já que não é por meio da telemedicina que se espera esse tipo de vínculo, e sim na atenção básica, onde o paciente deve ser conhecido e atendido na maioria das suas necessidades em saúde.

Um recurso estrutural fundamental para a regulação no SAMU é a disponibilidade de ambulâncias. Esse recurso foi previsto pela PNAU utilizando o critério populacional para definir seu quantitativo. Entretanto, o critério mais impactante para garantir o atendimento oportuno é o tempo resposta. Se a presteza é essencial para o atendimento de urgências com risco de vida, é necessário que haja ambulância disponível para garantir esse tempo resposta. A ambulância com médico e recursos tecnológicos mais complexos e diversos, a unidade de suporte avançado (USA), foi apontada como o recurso estrutural mais importante para o SAMU, que muitas vezes era insuficiente:

As distâncias percorridas pelas viaturas devem ser consideradas assim como a configuração geográfica. Tempo ouro, padrão, é de 12 minutos. Não é certo uma ambulância gastar 40 minutos para chegar em um local, seja pela distância ou pelo tipo de terreno. Entre ir, atender e voltar, não podemos ficar 3 horas sem uma ambulância USA.

Ficou evidente, segundo esse entrevistado, que as distâncias percorridas e outras dificuldades geográficas deveriam ser incluídas como critério de alocação do recurso ambulância. Entretanto, não houve consenso sobre a insuficiência desse recurso para o trabalho na regulação.

Se for medido o tempo de ocupação das ambulâncias, poderá ser detectada ociosidade.

A suposição de ociosidade de ambulâncias deve ser vista com cautela, já que o tempo resposta é o indicador que representa a efetividade do atendimento préhospitalar de urgência. 
Houve uma posição que valorizava menos o recurso estrutural, em benefício do processo de trabalho, no qual a ação do agente teria mais impacto, valorizando o aspecto semântico das regras, que se referem ao significado qualitativo e processual das práticas, associadas ao seu desempenho

Nós não precisamos de mais tecnologias. Precisamos de sistematização do cuidado.

Essa fala indica o equívoco de basear as soluções dos problemas de saúde unicamente nos recursos materiais.

Em relação ao tipo de atendimento, ficou evidente o predomínio de questões clínicas e doenças crônicas que precisam ser atendidas e acompanhadas no nível ambulatorial, em concordância com o indicado pelos parâmetros epidemiológicos:

Atendimento no SAMU é clínico, $68 \%$, sendo que $50 \%$ são cardiovasculares.

A literatura indica que os atendimentos clínicos, com efeito, são mais frequentes (TANNEBAUM; ARNAOLD, 2001; CHOMATAS, 2005; ALMEIDA, 2007; MEIRA, 2007).

Diferente das nossas expectativas, a necessidade de atender também às demandas mais sociais e menos técnicas não apareceu como um problema destacado nas entrevistas. Entretanto, a força da fala de um dos entrevistados confirma que a questão social não é marginal no SAMU:

Não dá para ficar no meio da regulação dizendo 'problema social não é comigo!'

A próxima questão a ser analisada problematiza quem é e como trabalha o médico regulador, frente a esse cenário presumido de escassez de recursos (internos e externos ao SAMU) e demandas complexas, tão bem ilustradas pela fala "tudo que não deu certo, vai pro SAMU".

\section{O médico, seu perfil, atitudes e a decisão clínica}

Essa categoria, que centraliza o profissional médico, indica a especificidade da ação desse agente social na mobilização dos recursos ambulância, referência e leito hospitalar, que são mobilizados a partir de dois critérios básicos: a existência do recurso e o reconhecimento da sua necessidade. Esse é um trabalho complexo e com grande impacto nos resultados de morbimortalidade. Para os entrevistados o regulador pode ser "herói, vilão e vítima, ao mesmo tempo".

A fala indica o conflito envolvido em regular os recursos existentes a partir de diferentes interesses (dos pacientes, do SAMU e do hospital, por exemplo). Ser 
ou não bem sucedido na atenção desses interesses e na condução de conflitos, permite que o regulador se torne herói ou vilão. Não ter garantido o recurso necessário para essa atribuição transforma o médico em vítima. Dito de outra forma, a mobilização desses recursos possibilita atendimentos cumprindo os sentidos da integralidade ou não.

Assim como sugerido pela política (BRASIL, 2003a), os entrevistados entendem que essa função reguladora é essencial para o trabalho no SAMU e sua relação com a rede. $\mathrm{O}$ médico regulador teve a prerrogativa de regulador sanitário do sistema (BRASIL, 2003a) reconhecida pelos entrevistados.

A prática de regulação utiliza de forma coerciva ou facilitadora recursos e regras nos seus aspectos normativos (em função dos direitos e obrigaçôes) e nos aspectos semânticos (significado qualitativo e processual das práticas). Uma coerção estrutural para essa prática foi exemplificada pelas condições de vínculo empregatício desses médicos:

A forma de contratação dos intervencionistas e reguladores é um problema. É municipal. Pela política não haveria precarização dos vínculos empregatícios. Acabou em RPA (Recibo de Pagamento Autônomo), inclusive com salários diferentes.

No Rio de Janeiro, a precariedade dos vínculos empregatícios dos profissionais de saúde é uma questão importante e quase dramática, até o momento. As condiçôes de trabalho apontadas desvalorizam a atividade regulatória e assistencial ("SAMU é um grande bico").

Não houve consenso de que essa dificuldade era antes de tudo estrutural, sendo atribuída pessoalmente ao médico e sua forma de utilizar seus recursos:

Estamos lutando para que o médico regulador seja o gestor. Se o médico faz pouco caso do seu papel de gestor, pior para o sistema.

Entretanto, trabalhar no SAMU ser considerado como "bico", ou seja, transitório e secundário, exige uma postura do Estado mais compatível com as determinações das portarias. Porém, existem outros intervenientes nas condições de trabalho, que com certeza impactavam a vinculação do profissional:

Fiz uma estimativa da necessidade de USA, mas sei que não adianta garantir todas as USA porque não vou conseguir lotar todos os médicos. Está difícil manter médicos nas ambulâncias pela violência, salário...

Outro tipo de problema apontado, que dificulta a fixação do médico, foi sua qualidade técnica:

Em relação aos médicos tem dois problemas, falta quantitativa e qualitativa 
Contribuiu com a baixa qualidade técnica do profissional a forma de contratação:

Tem pressão dos deputados quando demito um médico indicado por alguém. As pessoas ligam e dizem que é do gabinete do deputado pedindo pra reconsiderar ou então que o médico é filho de um juiz importante. Se eu demiti é porque seu trabalho era ruim, não dá pra reconsiderar.

A influência política na lotação dos médicos indicados representava uma tentativa de coerção pelos políticos por mobilização de recursos autoritativos, ou de capacidades que geram o comando (GIDDENS, 1984).

Os entrevistados entendiam o investimento em gestão do trabalho como fundamental para o protagonismo emancipador dos reguladores, e não acatavam as "indicações" políticas incondicionalmente. Reconheciam os benefícios de ter profissionais concursados, sem deixar de indicar que a postura do profissional pode independer da forma de vínculo. Também problematizaram outros limites da gestão, como a lei da responsabilidade fiscal.

Outro desafio para a regulação vem da própria concepção que o médico tem sobre seu trabalho no SAMU ("No imaginário dos médicos, a urgência é traumática"). Portanto, para a regulação ser mais “integral”, o aspecto normativo da PNAU (enquanto regra sob o ponto de vista dos direitos e obrigações) deve prevalecer, o que depende da concepção de urgência do profissional.

A compreensão da complexidade das necessidades de saúde traduzidas em demanda é indispensável para o regulador. As portarias propóem o conceito ampliado de urgência, visando incorporar a concepção desta do paciente. Afinal, a assistência é o resultado de forças que vêm da demanda e do conhecimento médico. O que é ofertado como assistência nasce dessa disputa:

Supervalorizam o trauma em detrimento do atendimento clínico e outros como obstétrico e psiquiátrico.

O apelo que o paciente do trauma suscita para a regulação tem uma legitimidade inquestionável; entretanto, as demandas transitam de uma escala que vai desde queixas vagas e entendidas como insignificantes (e não pertinentes ao SAMU), até situações com risco de incapacidade e letalidade. $\mathrm{O}$ não reconhecimento da queixa gera descaso do profissional, e a desvalorização das demandas gera perda de oportunidade de intervenção, já que o regulador é o condutor do atendimento ("Quem decide o que é urgência e emergência é o médico”). A concepção restrita sobre o tipo de demanda que deve ser objeto de 
intervenção não é privilégio do SAMU: influenciaram a assistência na atenção básica e na emergência hospitalar (O'DWYER et al., 2008):

Não mandamos ambulância pra paciente que não precisa. É importante dizer "não".

Nessa disputa de concepção de urgência, estão envolvidos valores individuais e sociais, que transitam entre polos opostos, que seriam atender a toda demanda ou atender exclusivamente à demanda de urgência, segundo o referencial médico. Como em todas as disputas, nascem estratégias para facilitar a negociação. As próximas falas ilustram uma posição de legitimação das demandas, coerente com a proposição da política, e necessária para driblar o privilégio da autonomia do médico na definição das demandas:

A regulação deve advogar sistematicamente pelo interesse do cidadão.

Em nenhum momento se contesta a informação que chega até nós pelo 192.

Schraiber (2008) analisou a prática médica, explicando o pouco envolvimento de médicos com o trabalho no SUS. Alegou que, desde 1930, os médicos atuavam como assalariados da medicina previdenciária ou filantrópica; porém, não concebiam seu trabalho como assalariado, mas como uma forma de "medicina social", próxima da filantropia, referindo-se ao altruísmo como símbolo da prática médica. Essa percepção persistiu na assistência do SUS, onde os baixos salários e o não reconhecimento do direito do usuário podem sugerir uma desresponsabilização do profissional com a "medicina social" (SCHRAIBER, 2008). Como consequência, corroboraria certa displicência na atuação profissional. A capacitação (um recurso) e a reflexão sobre o trabalho (uma atividade do agente) são necessárias para o resgate da responsabilidade profissional. Essa desresponsabilização foi apontada pelos gestores, e houve uma crítica contundente ao desempenho dos profissionais apontada por um deles:

Reclamo muito dos médicos que estão atendendo muito mal.

Sobre a capacitação dos profissionais, foram feitas poucas referências, mas suficientes para demonstrar sua deficiência no estado e o conhecimento dos entrevistados sobre a vinculação da capacitação com a proposta do SAMU:

Junto com o projeto, o ministério exige a proposta de capacitação dos Núcleos de Educação em Urgência.

Ainda que a implantação e o desenvolvimento dos Núcleos de Educação em Urgência (NEU) estejam aquém do esperado, ocupam papel fundamental para a qualificação dos profissionais (CICONET et al., 2008). 
É necessário reconhecer que capacitar não é só disponibilizar informações técnicas. Entretanto, a deficiência de conhecimento técnico específico foi diagnosticada e problematizada nos documentos da política, já que inexiste especialização em emergência para médicos e enfermeiros no Brasil. Essa lacuna deve ser suprida, porque é essencial para o trabalho em urgências.

Houve maior referência ao profissional como "vítima" e "vilão" do que como "herói". Foi bem evidenciada a relação entre a ação do agente em reconhecer a urgência e definir a condução do atendimento, com a utilização do recurso ambulância e do recurso externo, a capacidade instalada da rede. Para essas atribuições são necessários capacitação, envolvimento, reconhecimento da sua atuação e legitimidade junto aos serviços externos.

Foram diversas as formas de relação com a rede e estratégias de gestão apontadas pelos entrevistados, que estão indicadas na categoria a seguir.

\section{A assistência em rede, a gestão e a regulação}

Essa categoria de análise tratou da relação do SAMU com o sistema, enquanto a integralidade trata especialmente da integração da rede assistencial à urgência. A autoridade da regulação foi uma questão central para os entrevistados:

Falta de estrutura jurídico-administrativa pra regulação ter autoridade sanitária.

Os entrevistados vivenciavam no seu dia a dia a dificuldade de negociar acordos baseados nas referências estabelecidas entre os envolvidos, um recurso autoritativo, em cenários de divergência de interesses. Como a regulação envolve muitos atores, há a expectativa de que a formalidade jurídica seja necessária. Uma restrição apontada para o reconhecimento da "autoridade sanitária" estava na negociação envolver os gestores, sem a participação dos trabalhadores. O diretor de um hospital, ao acordar que o serviço era referência para uma especialidade, tinha que já ter discutido essa responsabilidade com os profissionais envolvidos. Segundo estes, a negociação tinha sido mais útil do que o estabelecimento formal da referência, apesar da necessidade desse recurso a ser mobilizado. $\mathrm{O}$ descaso com as referências instituídas contrasta com a consistência do referencial normativo da PNAU.

Outra questão estrutural indicada com forte impacto negativo sobre a regulação foi o financiamento. Uma precariedade referia-se à fragilidade dos municípios: 
O financiamento tem que aumentar. Os municípios mantêm a frota operacional e contratam o pessoal.

Esse conflito aumenta quando a regulação extrapola o ente federativo. Como na regionalização convivem municípios com realidades muito diversas, a pouca participação dos mais pobres (que eventualmente são os que mais demandam do sistema) pode ser menos tencionada se outros entes federativos assumirem mais o financiamento. Essa cooperação não era a regra. Não se deve esquecer que no SAMU o nível central já é um forte financiador; entretanto, em situações de precariedade de recursos muito gritante, outras responsabilidades não têm espaço para serem discutidas e incorporadas.

Uma estratégia prevista pela PNAU para qualificar a gestão entre entes diversos e potencializar a negociação para o enfrentamento desses conflitos, é a implantação dos diversos comitês gestores. Os gestores indicaram a potência dos comitês:

Os comitês regionais deveriam ter mais empoderamento. Ficar trabalhando os pactos. Trabalhar a grade de referência. Os pactos não são respeitados, os consórcios furam e fica por isso mesmo.

Infelizmente, até o final desse estudo (2008), os comitês gestores de urgência no nível municipal, regional e estadual não atuavam. Um tradicional comitê do estado do Rio de Janeiro, o primeiro SAMU regionalizado do Brasil, também estava desacreditado:

O comitê regional da Metro II não funciona mais. Há um tempão não se reúne, mais de 1 ano.

Foi descrita a potência gestora da atuação dos comitês:

Comitê gestor deve ter vida ativa, tem que ser dinâmico porque tem que ter penetração, é uma ferramenta de trabalho do médico regulador. Se o comitê atua junto aos serviços, ele, o médico regulador, não vai mais negociar vaga na hora

O comitê nacional gestor de urgências atuava no momento, mas não foi poupado de críticas ("O comitê nacional deve ser uma instância operacional, de planejamento e gestão").

Merece destaque uma reflexão crítica em torno das proposições da política, no caso desacreditando na atuação dos comitês:

Não acredito que o Comitê Estadual de Urgência, que está sendo implantado, melhore a situação. 
Certamente, em um estado com municípios grandes como o Rio de Janeiro, onde dois SAMU são regionalizados, um comitê estadual é um promovedor de acordos e de pactos de responsabilidades. A dificuldade da regionalização da urgência é compatível com a precariedade da regionalização no estado. Sabe-se que o Rio de Janeiro, apesar da capacidade assistencial instalada de serviços de saúde, sofreu uma regionalização tardia, se comparado a outros estados (VIANA et al., 2010). O comitê gestor de urgências do estado do Rio de Janeiro foi implantado em 2009.

Outro fator que pode "desqualificar" o comitê é uma representação desinteressada, destituída de instrumentos de gestão, ou engessada por questōes político-partidárias. Segue outra indicação de descrédito no comitê central:

Tem o documento da $1^{\text {a }}$ reunião do Comitê Gestor Nacional. Houve quatro reunióes até hoje. Comitê nasceu amorfo, instituiçôes sem clareza sobre a importância do comitê para a organização das urgências. Ganhou uma formalidade inicial. Na $1^{\mathrm{a}}$ reunião houve apresentação da política pros conselheiros, como momento de sedução dos conselheiros. Alguns não tinham nem idéia do que era a política.

Essa fala mostra que a simples indicação de representantes é insuficiente, e que as pessoas que representam seus grupos deveriam estar "seduzidas", antes de compor o comitê.

Uma função fundamental dos comitês é analisar informações no seu nível de atuação e repassá-las para os outros níveis. Os entrevistados garantiram que as informações eram produzidas de alguma forma, mas seu uso era exclusivamente para o gestor do próprio SAMU:

O SAMU não produz indicadores. Não sei se alguém faz isso.

Produzo informação de forma assistemática. O nível central não tem acesso aos indicadores.

Uma importante dificuldade de agregar-se a esse cenário de gestão insuficiente, que contribui com a baixa capacidade de atuação em rede, é o isolamento entre os serviços ("Relação com a rede é zero"). Esse isolamento tem como uma das causas a inadimplência desses gestores em produzir informaçóes para o planejamento, e como outra possível causa, uma tendência ao isolamento, em função das dificuldades individuais de cada serviço, desvinculando-se da rede:

Os hospitais não disponibilizam espontaneamente os leitos. 
Contribuiram com esse isolamento a autonomia excessiva e a pouca regulação sobre o trabalho médico:

Os hospitais não são cooperativos com os leitos porque em alguns serviços os chefes se sentem donos vitalícios, e há anos selecionam os pacientes que vão ocupar esses leitos"; e "Vivem em função do contexto de saber do profissional médico e não da necessidade do sistema. Todos constroem filtros.

A publicização da informação é uma estratégia de enfrentamento dessa autonomia exacerbada:

A informação dos leitos para regulação tem que ser pública e é tratada como informação privada da rede hospitalar.

Como instrumento de planejamento e fortalecimento das relações entre os diversos serviços, existem as normas produzidas pelo nível central, os mapas de serviços disponíveis e os leitos disponibilizados para a regulação, além dos esforços de cada um. Se a autonomia exacerbada contraria as normas, em um cenário de carência estrutural e de indisponibilidade de recursos médico-assistenciais, as relações pessoais garantem os fluxos e um mínimo de solidariedade, senão com o paciente, pelo menos com o colega médico:

A regulação é das relações pessoais.

Tem que ligar pra cada hospital duas vezes ao dia pra saber o que está disponível.

Não há cooperação com a regulação, a não ser a partir de relação pessoal. A gestão, a regulamentação, não garantem essa cooperação.

Lima (2008) destacou a indisponibilidade de recursos médico-assistenciais, principalmente no âmbito hospitalar e diagnóstico, como o principal problema para a coordenação do SAMU Metro II. Os entrevistados falaram dessa carência, também fazendo referência à importância das relações pessoais.

Indicamos, como aparece na fala seguinte, que o contexto de pouca cooperação não pode ser justificativa para atuar com descaso em relação aos problemas dos hospitais:

O déficit estrutural é muito grande. Algumas especialidades médicas como ortopedistas, neurocirurgião, não querem mais trabalhar na rede pública, não vale a pena. O SAMU referencia o paciente e o plantonista diz que não tem ortopedista. Tem que acabar aceitando porque era referência, aquele é o hospital de ortopedia. Não ter ortopedista é problema do hospital. 
$\mathrm{O}$ isolamento, o déficit de recursos e a incipiência da gestão geram consequências. Entre elas, houve destaque para uma hostilidade dos hospitais em relação ao SAMU, por acreditarem que estão atendendo mais porque o SAMU está criando uma nova demanda. Na verdade, o SAMU está resolvendo nos próprios domicílios muitas das demandas, e talvez esteja trazendo para a emergência pacientes que antes não chegavam ao hospital:

Só $15 \%$ dos atendimentos que fazemos vão pros hospitais"; e " $50 \%$ resolvem no telefone. Dos outros 50\%, 25\% resolvem no local.

No estado do Rio de Janeiro, a função observatório do sistema do SAMU está confirmando outro vazio assistencial, o advindo da atenção básica insuficiente:

A organização deve acontecer a partir do PSF. Só que a cobertura de PSF no Rio ainda é muito baixa.

Houve consenso (presente inclusive na PNAU) sobre a legitimidade da atenção básica como responsável pelo paciente e como porta de entrada. O que indicamos é que, se há carência estrutural da rede, e mesmo após a correção dessa carência, a urgência é uma porta de entrada possível dentro do sistema.

Apesar de reconhecerem o valor do conteúdo das portarias, havia um temor de que a realidade ofuscasse as determinações da PNAU. Outras falas indicaram a contradição entre a determinação normativa e a realidade:

Acho que tinha que ter uma gerência que tivesse poder real sobre os serviços, e não só no papel

Porque o papel é bonito, ta tudo escrito lá,..mas não tem nada a ver com a prática.

A descrença em relação ao que "é bonito no papel" atinge muitos profissionais. Descrédito que também está relacionado às pressões políticas e sua influência sobre as questôes técnicas ("As questôes políticas influenciam muito mais do que devia").

Apesar das dificuldades para a gestão em rede a partir do SAMU, os entrevistados também indicaram os avanços alcançados no curto espaço de tempo de atuação do SAMU:

A regulação está conquistando um espaço, estrutura é também espaço de mediação, legislação, o reconhecimento do colega do hospital.

Essa fala privilegia a mediação e a negociação para os avanços alcançados. 
A PNAU é recente e, apesar da escassa literatura sobre o SAMU, já se estabeleceu sua atuação crucial para o atendimento às urgências (REICHENHEIM et al., 2011). Atualmente há apoio para implementação de um novo componente do atendimento pré-hospitalar, a Unidade de Pronto Atendimento (UPA).

O estado do Rio de Janeiro, mais uma vez, diferenciou-se do restante do Brasil, e tem a maior implantação de UPA do país (dados do site do Ministério da Saúde em dezembro 2010). Nos últimos anos, também houve um incremento da Estratégia de Saúde da Família no estado, especialmente no município do Rio de Janeiro, que tinha a menor cobertura do estado em 2008.

Das três categorias analíticas, a que tratou do SAMU e suas atribuiçôes foi a única que indicou uma postura positiva por parte dos entrevistados, havendo mais concordância entre o previsto nos documentos e a opinião dos entrevistados.

Houve uma explicitação da função de "porta de entrada" do SAMU (sem atribuir ou negar positividade), mas não houve reconhecimento da sua importância em acolher o máximo de demandas, contribuindo para legitimá-lo perante a população. Essa seria uma prática compatível com a integralidade e que utilizaria a referência normativa como recurso facilitador.

Encontramos, nas entrevistas, justificativas para a rudeza da indicação de que não há relação com a rede. Foi indicada gestão esvaziada no isolamento entre os serviços, pela ausência dos indicadores de avaliação, dos comitês gestores atuando e da autoridade sanitária do regulador. Segundo os entrevistados, o vazio gerencial atingia os três entes federativos.

A descrença nos comitês é preocupante, já que eles são fundamentais para o planejamento a partir da informação repassada, assim como para os pactos da regionalização e entre os diversos serviços no atendimento integral às urgências. A insuficiência da gestão também foi apontada pelo financiamento.

Para uma primeira descrição nacional do SAMU, deveria haver informação consolidada, o que não existe, segundo os gestores, apesar dos indicadores propostos pela política. Os comitês atuantes seriam um espaço para negociar essa informação e traduzi-la em planejamento de ações. 
Essa análise refere-se prioritariamente ao Estado do Rio de Janeiro. Pela diversidade do país, são necessários outros estudos analisando a capacidade de regulação em circunstâncias diversas, e com outros recursos.

A integralidade foi discutida no seu componente organizacional, que, segundo as falas desses gestores, ainda era muito frágil. A pouca explicitação de atender todas as demandas foi compatível com a pouca referência aos problemas sociais.

As três categorias indicadas a partir da consciência discursiva desses gestores trataram de questōes enigmáticas não só para o SAMU, mas para o SUS, como: o empenho normativo não cumprido na prática; o baixo investimento no profissional; a rede insuficiente; e a baixa integração dos serviços ${ }^{1}$.

\section{Referências}

ALMEIDA, A.C. A avaliação da implantação e do desenvolvimento do sistema público municipal de atendimento pré-hospitalar móvel da cidade do Recife. 2007. $204 \mathrm{f}$. Dissertação (Mestrado em Saúde Pública) - Centro de Pesquisas Aggeu Magalhães, Recife, 2007.

BITTENCOURT, R.J.; HORTALE, V.A. Intervençôes para solucionar a superlotação nos serviços de emergência hospitalar: uma revisão sistemática. Cadernos de Saúde Pública, Rio de Janeiro, v. 25, n.7, p.1439-1454, jul. 2009.

BRASIL. Ministério da Saúde. Portaria no 1863, de 29 de setembro de 2003a. Institui a Politica Nacional de Atenção às Urgências. Publicada no Diário Oficial da Nação no dia 06 de outubro de 2003, seção 1, p. 58, coluna 1.

BRASIL. Ministério da Saúde. Portaria no 1864, de 29 de setembro de 2003b. Institui o Componente pré-hospitalar móvel da PNAU - o SAMU. Publicada no Diário Oficial da Nação no dia 06 de outubro de 2003, seção 1, p. 57, coluna 1.

CARRET, M.L.V.; FASSA, A.G.; DOMINGUES, M.R. Prevalência e fatores associados ao uso inadequado do serviço de emergência: uma revisão sistemática da literatura. Cadernos de Saúde Pública, Rio de Janeiro, v. 25, n.1, p.7-28, jan. 2009.

CHOMATAS, M. Integração de saberes e práticas na organização do SAMU de Curitiba PR. Divulg. Saúde Debate, Rio de Janeiro, v. 32, p.90-95, maio 2005.

CICONET, R.M.; MARQUES, G.Q.; LIMA, M.A.D.S. Educação em serviço para profissionais do Serviço de Atendimento Móvel de Urgência (SAMU): relato da experiência de Porto Alegre - RS. Interface - Comunic, Saúde, Educ, v.12, n.26, p.659-666, jul./set. 2008. GIDDENS, A. A constituiçāo da Sociedade. São Paulo: Martins Fontes, 1984. 458p.

HOLLANDER, J.E.; PINES, J.M. The emergency department crowding paradox: the longer you stay, the less care you get. Ann Emerg. Med, Dallas, v.50, n.5, p.497-499, Nov. 2007. 
KALEMOGLU, M. et al. Non-urgent patients in an emergency medical service. Rev Med Chile, Santiago, v.132, p.1085-1087, 2004.

LIMA, J.C. Agir comunicativo e coordenação em sistemas de serviços de saúde: um estudo no serviço de atendimento móvel de urgência da região metropolitana II do estado do Rio de Janeiro. 2008. 167 f.Tese (Doutorado em Saúde Coletiva). - Escola Nacional de Saúde Pública Sergio Arouca, ENSP/FIOCRUZ, Rio de Janeiro, 2008.

MACHADO, C.V.; SALVADOR, F.G.F.; O’DWYER, G. O Serviço de Atendimento Móvel de Urgência no Brasil: uma análise da política nacional. Revista de Saúde Pública São Paulo, v.45, n.3, p.519-528, jun. 2011.

MATTOS, R.A. Os sentidos da integralidade: algumas reflexões acerca de valores que merecem ser defendidos. In: PINHEIRO, R.; MATTOS, R.A. (Org.). Os sentidos da integralidade na atenção e no cuidado à saúde. Rio de Janeiro: UERJ/IMS. 2001. p. 39-64.

MEIRA, M.M. Diretrizes para a educação permanente no serviço de atendimento móvel de urgência (SAMU). 2007. 157 f. Dissertação (Mestrado em Filosofia, saúde e sociedade) Universidade Federal de Santa Catarina, Santa Catarina, 2007.

O’DWYER, G.; MATTA, I.E.A.; PEPE, V.L.E . Avaliação dos serviços hospitalares de emergência do estado do Rio de Janeiro. Ciência e Saúde Coletiva, Rio de Janeiro, v.13, n.5, p.1637-1648, 2008.

O’DWYER, G.; MATTOS, R.A. Teoria da Estruturação de Giddens e os estudos de práticas avaliativas. Physis Revista de Saúde Coletiva, Rio de Janeiro, v.20 n.2, p.609-623, 2010.

REICHENHEIM, M.E. et al. Violência e lesões no Brasil: efeitos, avanços alcançados e desafios futuros. The Lancet, maio, p. 75-89, 2011.

SCHRAIBER, L.B. O médico e suas interaçôes: a crise dos vínculos de confiança. São Paulo: Hucitec, 2008. 254p.

TANNEBAUM, R.D.; ARNAOLD, J.L. Emergency Medicine in Southern Brazil. Ann. Emerg. Med., Dallas, v.37, n.2, supl., p.223-228, Feb. 2001.

VIANA, A.L.D.; LIMA, L.D.; FERREIRA, M.P. Condicionantes estruturais da regionalização na saúde: tipologia dos Colegiados de Gestão Regional. Ciência e Saúde Coletiva, Rio de Janeiro, v.15, n.5, p.2317-2326, 2010.

\section{Nota}

${ }^{1}$ G. O’Dwyer participou da redação do artigo, da coleta e da análise dos dados; R. Mattos participou da redação do artigo e da análise dos dados. 


\section{The SAMU, the regulation in the State of Rio de Janeiro and integral care according to managers of the three government levels}

The SAMU is a priority politics for the present government. This study aimed to discuss the potential of integral care practices within the SAMU, analyzing the care to the emergency cases by key management actors. Methodology was based on Giddens's Structuration Theory, linking structure and action, which was investigated by means of discursive consciousness. We interviewed managers of three federal entities which related their regulation practices of SAMU in the State of Rio de Janeiro. The axes of analysis were: the SAMU, its features, functions, and social issue, the doctor, his profile, attitudes and clinical decision making, and assistance in networking, management and regulation. No integrated assistance for structural failure of primary care and precariousness in the referral hospitals was pointed. Precarious training and employment relationships hinder the management in the SAMU. There was ineffectiveness of the management committees of various levels and there was no information production. It was highlighted the privilege of regulation as a monitoring system and attention to the emergency room to evaluate the performance of the network and the regionalization of care.

> Key words: SAMU, integral care, attention to emergencies and emergency policies. 